University of Wollongong

Research Online

Faculty of Engineering and Information

Faculty of Engineering and Information

Sciences - Papers: Part A

Sciences

$1-1-2013$

\title{
Effects of caustic cleaning on pore size of nanofiltration membranes and their rejection of trace organic chemicals
}

\author{
Alexander Simon \\ University of Wollongong, asimon@uow.edu.au \\ James A. McDonald \\ University Of New South Wales \\ Stuart J. Khan \\ University Of New South Wales, s.khan@unsw.edu.au \\ William E. Price \\ University of Wollongong, wprice@uow.edu.au \\ Long D. Nghiem \\ University of Wollongong, longn@uow.edu.au
}

Follow this and additional works at: https://ro.uow.edu.au/eispapers

Part of the Engineering Commons, and the Science and Technology Studies Commons

\footnotetext{
Research Online is the open access institutional repository for the University of Wollongong. For further information
} contact the UOW Library: research-pubs@uow.edu.au 


\title{
Effects of caustic cleaning on pore size of nanofiltration membranes and their rejection of trace organic chemicals
}

\begin{abstract}
The aim of this study was to assess the impact of caustic cleaning on the rejection of three different trace organic chemical (TrOC) groups (i.e. neutral hydrophilic, neutral hydrophobic and negatively charged) by two nanofiltration (NF) membranes - namely NF270 and NF90. Chemical cleaning was simulated by exposing virgin membrane samples to commercial caustic cleaning formulations as well as sodium hydroxide solutions containing analytical grade additives such as sodium dodecyl sulfate or ethylenediaminetetraacetic acid. The membrane average pore size before and after exposure to a commercially available caustic cleaning formulation was determined based on the pore transport model. The results show that caustic chemical cleaning could cause an increase in the membrane pore size, leading to an increase in permeability and decrease in rejection of conductivity. The impact of caustic cleaning on the pore size and solute rejection was a function of the membrane active skin layer and the chemistry of the cleaning formulation. Caustic cleaning led to a small increase in pore size of the NF270 membrane and resulted in a notable increase in the permeability and salt passage. By contrast, the impact on the NF90 membrane was negligible. The influence of caustic cleaning on TrOC rejection was dependent on physical characteristics of each TrOC including their molecular size, charge, and hydrophobicity. The rejection of neutral and hydrophobic TrOC by the NF270 membrane decreased significantly after exposure to caustic cleaning formulation. However, because the rejection of negatively charged TrOC is governed mostly by electrostatic interaction, their rejection was not significantly affected by caustic cleaning.
\end{abstract}

\section{Keywords}

trace, rejection, their, membranes, chemicals, organic, size, effects, caustic, pore, nanofiltration, cleaning

\section{Disciplines}

Engineering | Science and Technology Studies

\section{Publication Details}

Simon, A., McDonald, J. A., Khan, S. J., Price, W. E. \& Nghiem, L. D. (2013). Effects of caustic cleaning on pore size of nanofiltration membranes and their rejection of trace organic chemicals. Journal of Membrane Science, 447 153-162. 


\title{
Effects of caustic cleaning on pore size of nanofiltration membranes and their rejection of trace organic chemicals
}

\author{
Revised Manuscript Submitted to \\ Journal of Membrane Science
}

June 2013

Alexander Simon ${ }^{1}$, James A. McDonald ${ }^{2}$, Stuart J. Khan ${ }^{2}$, William E. Price ${ }^{3}$, Long D. Nghiem ${ }^{1, *}$

${ }^{1}$ School of Civil Mining and Environmental Engineering

The University of Wollongong, Wollongong, NSW 2522, Australia

${ }^{2}$ Water Research Centre

The University of New South Wales, Sydney, NSW 2052, Australia

${ }^{3}$ School of Chemistry

The University of Wollongong, Wollongong, NSW 2522, Australia

* Corresponding author: Long Duc Nghiem, Email longn@uow.edu.au; Tel: +61 242214590. 


\begin{abstract}
The aim of this study was to assess the impact of caustic cleaning on the rejection of three different trace organic chemical (TrOC) groups (i.e. neutral hydrophilic, neutral hydrophobic and negatively charged) by two nanofiltration (NF) membranes $\square$ namely NF270 and NF90. Chemical cleaning was simulated by exposing virgin membrane samples to commercial caustic cleaning formulations as well as sodium hydroxide solutions containing analytical grade additives such as sodium dodecyl sulfate or ethylenediaminetetraacetic acid. The membrane average pore size before and after exposure to a commercially available caustic cleaning formulation was determined based on the pore transport model. The results show that caustic chemical cleaning could cause an increase in the membrane pore size, leading to an increase in permeability and decrease in rejection of conductivity. The impact of caustic cleaning on the pore size and solute rejection was a function of the membrane active skin layer and the chemistry of the cleaning formulation. Caustic cleaning led to a small increase in pore size of the NF270 membrane and resulted in a notable increase in the permeability and salt passage. By contrast, the impact on the NF90 membrane was negligible. The influence of caustic cleaning on TrOC rejection was dependent on physical characteristics of each TrOC including their molecular size, charge, and hydrophobicity. The rejection of neutral and hydrophobic TrOC by the NF270 membrane decreased significantly after exposure to caustic cleaning formulation. However, because the rejection of negatively charged TrOC is governed mostly by electrostatic interaction, their rejection was not significantly affected by caustic cleaning.
\end{abstract}

Keywords: Nanofiltration, trace organic chemicals (TrOC), physicochemical properties, caustic cleaning, pore size. 


\section{Introduction}

Trace organic chemicals (TrOC) such as pharmaceutically active compounds, endocrine disrupting compounds, and pesticides are continuously released - either directly or indirectly into municipal sewers. Some of these TrOC are poorly removed by conventional wastewater treatment processes and thus they can be detected in surface water [1-3] and in some rare cases even in drinking water $[4,5]$. Although these TrOC usually occur in the aquatic environment and drinking water at concentrations well below the minimum acute therapeutic dose or toxicity level, their potential impact on human health and the environment over an extended period is largely unknown and is of significant concern to the public and scientific community [6]. Therefore, reliable removal of TrOC from municipal wastewater is essential for the protection of public health, particularly when effluent is intended for water reuse applications.

Driven by growing population densities, urbanisation, and the freshwater pollution, water reuse (or recycling) has become a pragmatic and sustainable approach to secure a stable supply of clean water beyond what is available from the hydrological cycle. Water reuse involves a range of advanced treatment processes such as nanofiltration (NF) or reverse osmosis (RO) membrane filtration, ozonation, activated carbon adsorption and/or UV oxidation. Among these technologies, NF/RO membrane applications have become an integral component of many water reuse schemes around the world [7]. Although NF/RO membrane processes can remove most TrOC reliably by steric hindrance (size exclusion), adsorption and/or electrostatic interaction (charge exclusion), TrOC removal in full-scale applications can be affected by inevitable membrane fouling (caused by deposition of organic and inorganic matter and/or the formation of biofilms) which necessitates periodic chemical cleaning [8-10]. However, to date, little is known about the impact of chemical cleaning on the rejection of TrOC by NF/RO membranes $[11,12]$.

Commonly used membrane cleaning reagents include acidic, caustic, surfactants and metal chelating reagents, which are often used in combination or in sequence to restore the membrane performance. Among these reagents, caustic formulations have been shown to exert a considerable impact on membrane performance immediately after chemical cleaning $[9,10,13$, 14]. This phenomenon has been recently explained by conformational rearrangements of polymeric chains in the membrane active skin layer (membrane swelling) as a response to the deprotonation of the membranes functional groups in a high $\mathrm{pH}$ environment [9]. Due to hysteresis, the polyamide chains do not immediately return to their normal position when the 
membranes are subsequently used at near neutral $\mathrm{pH}$. In addition, when used in a combination with a caustic reagent, metal chelating reagents and surfactants can adsorb and/or complex to the membrane polymer, which can further aggravate the impact of chemical cleaning on membrane performance $[9,13]$. In fact, chemical cleaning with commercial caustic cleaning formulations, which usually contain a range of cleaning additives (i.e. surfactants and metal chelating reagents), have been often observed to recover the membrane flux to values above $100 \%$ of that achieved prior to cleaning $[9,13,15,16]$.

The aim of this study was to investigate the impact of caustic cleaning formulations on the rejection of TrOC by two NF membranes. These caustic cleaning formulation are usually used to control organic fouling, which is the predominant type of membrane fouling in water-reuse and surface water filtration applications [17]. Chemical cleaning was simulated by exposing virgin membrane samples to analytical grade and commercial cleaning formulations. Changes in membrane average pore size, surface hydrophobicity and permeability, were systematically correlated to the variation in the rejection and physico-chemical properties of the TrOC. The mechanisms underlining the influence of chemical cleaning on TrOC rejection were elucidated and discussed.

\section{Materials and Methods}

\subsection{Membranes}

Two thin film composite nanofiltration membranes - namely NF270 and NF90 (Dow FilmTec, Minneapolis, MN, USA) - were tested. These membranes have a semi-aromatic polyamide piperazine and a fully aromatic polyamide membrane active skin layer, respectively, on top of a porous polysulphone supporting structure [18]. The active skin layer thickness of the NF270 and NF90 membrane is $21 \pm 5 \mathrm{~nm}$ and $218 \pm 40 \mathrm{~nm}$, respectively [19]. According to the manufacturer, the molecular weight cut-offs of the NF270 and NF90 membranes are 300-400 and 200 Daltons, respectively. The nominal permeate fluxes are 52 and $32 \mathrm{~L} / \mathrm{m}^{2} \mathrm{~h}$, respectively. The recommended operational $\mathrm{pH}$ range of the NF270 membrane is between $\mathrm{pH} 3$ and 10 and that of the NF90 membrane is between $\mathrm{pH} 2$ and 11. A more caustic (i.e. $\mathrm{pH}$ 12) or acidic condition (i.e. $\mathrm{pH} 1$ ) can be used for cleaning $30 \mathrm{~min}$ or less [20]. 


\subsection{Cleaning formulations}

Two commercially available caustic cleaning formulations - namely MC11 (IMCD, Mulgrave, VIC, Australia) and PC98 (NALCO, Botany, NSW, Australia) - were used. The MC11 and PC98 were supplied in powder and liquid form, respectively. Chemical cleaning solutions were prepared according to the specifications of the manufacturer by separately dissolving $25 \mathrm{~g} / \mathrm{L}$ of the MC11 and 4\% (wt/wt) of the PC98 in Milli-Q water to obtain the final working solutions with a pH of 11.2 and 11.0 at $20 \pm 1{ }^{\circ} \mathrm{C}$, respectively. Although the exact compositions of these chemical cleaning formulations are proprietary information, it is understood that the MC11 formulation is a blend of detergent builders, $\mathrm{pH}$ buffers, and metal chelating reagents such as ethylenediaminetetraacetic acid (EDTA), sodium tripolyphosphate (STP) and trisodium phosphate (TSP). On the other hand, PC98 contains amphoteric surfactants and the chelating reagent EDTA.

Two additional caustic cleaning formulations were also prepared using analytical grade chemicals to obtain $5.4 \mathrm{mM}$ EDTA or $10 \mathrm{mM}$ sodium dodecyl sulfate (SDS) in a $\mathrm{NaOH}$ solution at $\mathrm{pH}$ 11.5. These cleaning solutions were designated as $\mathrm{NaOH}+\mathrm{SDS}$ and $\mathrm{NaOH}+\mathrm{EDTA}$. It is noteworthy that no specifications from the membrane manufacturers could be found in the literature regarding the concentration limits of surfactants or metal chelating reagents in cleaning solutions despite their common use as key ingredients in commercial cleaning formulations.

\subsection{Model trace organic contaminants}

A set of 35 TrOC with molecular weights ranging from 138 to 376 Daltons and a wide range of

physico-chemical properties were used for this study (Table 1). These compounds were purchased from Sigma Aldrich (Castle Hill, NSW, Australia) as analytical standards. Based on their physico-chemical properties, these TrOC could be classified into three groups: neutral hydrophilic $(\log \mathrm{D}<3)$, neutral hydrophobic $(\log \mathrm{D} \geq 3)$, and negatively charged (Table 1$)$. Log $\mathrm{D}$ is defined as the effective log n-octanol-water distribution ratio, which takes into account the speciation of the compound as a function of the solution $\mathrm{pH}$ [21]. A stock solution containing 5 $\mathrm{mg} / \mathrm{L}$ of each $\mathrm{TrOC}$ was prepared with methanol, stored at $-18{ }^{\circ} \mathrm{C}$ in the dark, and used within 1 month.

Table 1: Key physico-chemical properties of the TrOC. 


\begin{tabular}{|c|c|c|c|c|c|c|}
\hline & Compound & $\begin{array}{l}\text { Chemical } \\
\text { Formula }^{\text {a }}\end{array}$ & $\begin{array}{c}\mathrm{MW}^{\mathrm{a}} \\
\text { (Dalton) }\end{array}$ & $\begin{array}{l}\text { Equivalent width } \\
(\mathrm{nm})^{\mathrm{b}}\end{array}$ & $\begin{array}{c}\log \mathrm{D} \\
\text { at } \mathrm{pH} 8^{\text {a }}\end{array}$ & $\mathrm{pK}_{\mathrm{a}}^{\mathrm{a}}$ \\
\hline \multirow{13}{*}{ 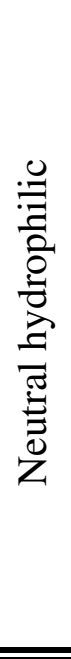 } & Paracetamol & $\mathrm{C}_{8} \mathrm{H}_{9} \mathrm{NO}_{2}$ & 151.16 & 0.60 & 0.33 & $9.86 ; 1.72$ \\
\hline & Triamterene & $\mathrm{C}_{12} \mathrm{H}_{11} \mathrm{~N}_{7}$ & 253.26 & 0.61 & 1.15 & $-1.2 ; 6.28$ \\
\hline & Caffeine & $\mathrm{C}_{8} \mathrm{H}_{10} \mathrm{~N}_{4} \mathrm{O}_{2}$ & 194.19 & 0.70 & -0.13 & 0.73 \\
\hline & Estriol & $\mathrm{C}_{18} \mathrm{H}_{24} \mathrm{O}_{3}$ & 288.4 & 0.70 & 2.94 & 10.25 \\
\hline & Androstenedione & $\mathrm{C}_{19} \mathrm{H}_{26} \mathrm{O}_{2}$ & 286.4 & 0.74 & 2.9 & 8.78 \\
\hline & Carbamazepine & $\mathrm{C}_{15} \mathrm{H}_{12} \mathrm{~N}_{2} \mathrm{O}$ & 236.27 & 0.76 & 1.89 & $13.94 ;-0.49$ \\
\hline & Atrazine & $\mathrm{C}_{8} \mathrm{H}_{14} \mathrm{ClN}_{5}$ & 215.68 & 0.79 & 2.63 & 2.35 \\
\hline & Primidone & $\mathrm{C}_{12} \mathrm{H}_{14} \mathrm{~N}_{2} \mathrm{O}_{2}$ & 218.25 & 0.79 & 0.4 & $12.26 ;-1.07$ \\
\hline & Dilantin & $\mathrm{C}_{15} \mathrm{H}_{12} \mathrm{~N}_{2} \mathrm{O}_{2}$ & 252.27 & 0.80 & 2.36 & $8.33 ;-2.81$ \\
\hline & Fluoxetine & $\mathrm{C}_{17} \mathrm{H}_{18} \mathrm{~F}_{3} \mathrm{NO}$ & 309.22 & 0.85 & 1.91 & 10.05 \\
\hline & Meprobamate & $\mathrm{C}_{9} \mathrm{H}_{18} \mathrm{~N}_{2} \mathrm{O}_{4}$ & 218.25 & 0.86 & 0.7 & $13.09 ;-1.09$ \\
\hline & Trimethoprim & $\mathrm{C}_{14} \mathrm{H}_{18} \mathrm{~N}_{4} \mathrm{O}_{3}$ & 290.32 & 0.88 & 0.73 & $1.32 ; 7.45$ \\
\hline & Omeprazole & $\mathrm{C}_{17} \mathrm{H}_{19} \mathrm{~N}_{3} \mathrm{O}_{3} \mathrm{~S}$ & 345.42 & 0.92 & 2.33 & $4.72 ; 8.78$ \\
\hline \multirow{12}{*}{ 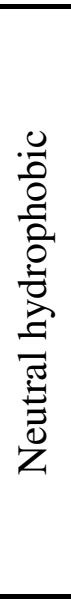 } & Testosterone & $\mathrm{C}_{19} \mathrm{H}_{28} \mathrm{O}_{2}$ & 288.4 & 0.63 & 3.47 & 15.06 \\
\hline & Triclosan & $\mathrm{C}_{12} \mathrm{H}_{7} \mathrm{Cl}_{3} \mathrm{O}_{2}$ & 289.54 & 0.64 & 4.76 & 7.8 \\
\hline & Etiocholanolone & $\mathrm{C}_{19} \mathrm{H}_{30} \mathrm{O}_{2}$ & 290.4 & 0.65 & 3.75 & 15.13 \\
\hline & Androsterone & $\mathrm{C}_{19} \mathrm{H}_{30} \mathrm{O}_{2}$ & 290.4 & 0.65 & 3.93 & 15.14 \\
\hline & Linuron & $\mathrm{C}_{9} \mathrm{H}_{10} \mathrm{Cl}_{2} \mathrm{~N}_{2} \mathrm{O}_{2}$ & 249.09 & 0.70 & 3.2 & $12.13 ;-1.04$ \\
\hline & 17a-estradiol & $\mathrm{C}_{18} \mathrm{H}_{24} \mathrm{O}_{2}$ & 272.4 & 0.74 & 4.15 & 10.27 \\
\hline & 17b-estradiol & $\mathrm{C}_{18} \mathrm{H}_{24} \mathrm{O}_{2}$ & 272.4 & 0.74 & 4.13 & 10.27 \\
\hline & Estrone & $\mathrm{C}_{18} \mathrm{H}_{22} \mathrm{O}_{2}$ & 270.4 & 0.76 & 3.68 & 10.25 \\
\hline & t-Octylphenol & $\mathrm{C}_{14} \mathrm{H}_{22} \mathrm{O}$ & 206.32 & 0.84 & 4.93 & 10.15 \\
\hline & 17a-ethynylestradiol & $\mathrm{C}_{20} \mathrm{H}_{24} \mathrm{O}_{2}$ & 296.4 & 0.85 & 4.1 & 10.24 \\
\hline & Clozapine & $\mathrm{C}_{18} \mathrm{H}_{19} \mathrm{ClN}_{4}$ & 326.28 & 0.90 & 3.8 & 7.33 \\
\hline & Amitriptyline & $\mathrm{C}_{20} \mathrm{H}_{23} \mathrm{~N}$ & 277.4 & 0.92 & 3.72 & 9.18 \\
\hline \multirow{10}{*}{ 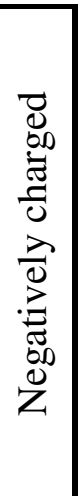 } & Salicilic Acid & $\mathrm{C}_{7} \mathrm{H}_{6} \mathrm{O}_{3}$ & 138.12 & 0.26 & -1.14 & 3.01 \\
\hline & Ibuprofen & $\mathrm{C}_{13} \mathrm{H}_{18} \mathrm{O}_{2}$ & 206.28 & 0.64 & 0.36 & 4.41 \\
\hline & Sulfamethoxazole & $\mathrm{C}_{10} \mathrm{H}_{11} \mathrm{~N}_{3} \mathrm{O}_{3} \mathrm{~S}$ & 253.28 & 0.64 & -0.9 & $5.81 ; 1.39$ \\
\hline & Naproxen & $\mathrm{C}_{14} \mathrm{H}_{14} \mathrm{O}_{3}$ & 230.25 & 0.76 & -0.06 & 4.84 \\
\hline & TCEP & $\mathrm{C}_{9} \mathrm{H}_{15} \mathrm{O}_{6} \mathrm{P}$ & 250.91 & 0.78 & -5.97 & 4.05 \\
\hline & Gemfibrozil & $\mathrm{C}_{15} \mathrm{H}_{22} \mathrm{O}_{3}$ & 250.33 & 0.78 & 1.26 & 4.75 \\
\hline & Diclofenac & $\mathrm{C}_{14} \mathrm{H}_{11} \mathrm{Cl}_{2} \mathrm{NO}_{2}$ & 296.14 & 0.78 & 0.57 & $4.18 ;-2.25$ \\
\hline & DEET & $\mathrm{C}_{12} \mathrm{H}_{17} \mathrm{NO}$ & 191.27 & 0.81 & 1.96 & -1.37 \\
\hline & Ketoprofen & $\mathrm{C}_{16} \mathrm{H}_{14} \mathrm{O}_{3}$ & 254.28 & 0.83 & -0.64 & 4.23 \\
\hline & Enalapril & $\mathrm{C}_{20} \mathrm{H}_{28} \mathrm{~N}_{2} \mathrm{O}_{5}$ & 376.45 & 1.24 & -0.45 & $3.15 ; 5.43$ \\
\hline
\end{tabular}

${ }^{a}$ Based on SciFinder Scholar

${ }^{\mathrm{b}}$ Calculated using Molecular Modelling Pro

\subsection{Filtration protocol}

A laboratory-scale cross-flow NF/RO filtration system was used and consisted of a cross flow stainless steel cell, a Hydra-Cell pump (Wanner Engineering Inc., Minneapolis, MN), a 
temperature control unit (Neslab RTE 7), a digital flow meter (Optiflow 1000, Agilent Technologies, Palo Alto, CA) connected to a PC, and a rotameter to measure the concentrate flow. The cross flow cell had an effective membrane area of $40 \mathrm{~cm}^{2}(4 \mathrm{~cm} \times 10 \mathrm{~cm})$ and a channel height of $2 \mathrm{~mm}$. Further details of this filtration system are available elsewhere [22].

Prior to each experiment, the membrane samples were rinsed with Milli-Q water to remove any protective chemicals. They were then compacted for one hour with Milli-Q water at 18 bar. To determine the rejection of TrOC, 10 litre of a background electrolyte solution containing $1 \mathrm{mM}$ $\mathrm{CaCl}_{2}, 20 \mathrm{mM} \mathrm{NaCl}$ and $1 \mathrm{mM} \mathrm{NaHCO} 3(\mathrm{pH}=8)$ was used. The stock solution of TrOC was added to the feed solution to obtain approximately $750 \mathrm{ng} / \mathrm{L}$ of each compound. The filtration was then conducted at a permeate flux, temperature and cross-flow velocity of $42 \mathrm{~L} / \mathrm{m}^{2} \mathrm{~h}, 20 \pm$ $0.1{ }^{\circ} \mathrm{C}$ and $23.6 \mathrm{~cm} / \mathrm{s}$, respectively. Permeate and feed samples $(500 \mathrm{~mL}$ each) were collected for analysis after 1 and $24 \mathrm{~h}$ of filtration. The observed rejection $\left(\mathrm{R}_{\mathrm{ob}}\right)$ is calculated by:

$$
\mathrm{R}_{\mathrm{ob}}=1-\frac{\mathrm{c}_{\mathrm{p}}}{\mathrm{c}_{\mathrm{f}}}
$$

Where $c_{\mathrm{f}}$ and $\mathrm{c}_{\mathrm{p}}$ are the solute concentration in the feed and permeate solution, respectively.

\subsection{Cleaning simulation protocol}

Chemical cleaning was simulated by immersing the membrane samples in the cleaning solution for $18 \mathrm{~h}$. The cleaning solution was kept at $35 \pm 1{ }^{\circ} \mathrm{C}$ and was constantly agitated using a shaking water bath (SWB20, Ratek Instruments, Victoria, Australia). The membrane samples were removed from the cleaning solution, gently rinsed with Milli-Q water and used for filtration experiments on the same day. For comparison purposes, virgin (without chemical cleaning) membrane samples were also immersed in Milli-Q water at $35 \pm 1{ }^{\circ} \mathrm{C}$ for $18 \mathrm{~h}$ prior to any filtration experiment. This chemical cleaning simulation represents one cleaning event for a severely fouled membrane as recommended by the manufacturer [23]. It can also represent a series of routine preventative chemical cleaning protocols of $1 \mathrm{~h}$ either every 3 or 6 months over 4.5 years, as suggested by BWA water additives (the manufacturer of the cleaning formulation MC11) [24]. In practice, there is a fouling layer on the membrane surface before chemical cleaning is required. To some extent, the fouling layer could shield the membrane surface from direct exposure to the cleaning solution. On the other hand, foulant residues on the membrane surface after chemical cleaning may also interfere with the measurement of the membrane surface 
properties [16]. Thus, the cleaning procedure simulated in this study allows for a systematic examination of any changes in the membrane properties and separation efficiency without any interference of the foulant residues on the membrane surface. This cleaning protocol has been used successfully by several other research groups [15, 25-27].

\subsection{Trace organic compound analyses}

The analysis of the TrOC was based on a previously developed analytical method involving a solid phase extraction (SPE) procedure followed by determination using a liquid chromatography tandem mass spectrometry (LC-MS/MS) system [28]. Prior to the extraction, $50 \mathrm{ng}$ of an isotopically labelled version of each analyte was added to $500 \mathrm{~mL}$ of sample. The analytes were then extracted using $5 \mathrm{~mL}, 200 \mathrm{mg}$ hydrophilic/lipophilic balance (HLB) SPE cartridges (WAT106202, Oasis, Ohio, USA). The cartridges were pre-conditioned with $5 \mathrm{~mL}$ of tert-butyl methyl ether, $5 \mathrm{~mL}$ of methanol and $5 \mathrm{~mL}$ of Milli-Q water. Sample extraction was carried out at a flow rate of approximately $3 \mathrm{~mL} / \mathrm{min}$. Subsequently, the cartridges were rinsed with $5 \mathrm{~mL}$ Milli-Q water and dried for $30 \mathrm{~min}$ using high purity nitrogen. The loaded cartridges were stored in a sealed plastic bag at $-18{ }^{\circ} \mathrm{C}$ in the dark until elution for LC-MS/MS analysis. The LCMS/MS system consisted of an Agilent (Palo Alto, CA, USA) 1200 series high-performance liquid chromatography (HPLC) system, which was equipped with a Luna C18 (Phenomenex, Torrence CA, USA) column and an API 4000 triple quadruple mass spectrometer (Applied Biosystems, Foster City, CA, USA).

\subsection{Membrane characterisation}

\subsubsection{Contact angle}

The hydrophobicity of the membrane surface was measured using a Rame-Hart Goniometer (Model 250, Rame-Hart, Netcong, NJ) following the standard sessile drop method. Prior to each measurement, the membrane sample was air-dried. Milli-Q water was used as the reference solvent. At least 5 Milli-Q water droplets were applied to each membrane sample and the contact angle was immediately measured on both sides of the droplet.

\subsubsection{Membrane permeability}

A bench scale dead-end filtration system was used to measure the permeability of virgin and chemically cleaned membrane [29]. The system consisted of a stainless steel stirred cell with an active membrane surface area of $21.2 \mathrm{~cm}^{2}$. A digital balance (Model Mettler Toledo, Ohio, USA) 
connected to a personal computer was used to monitor the permeate flow. The membrane was initially compacted for $1 \mathrm{~h}$ using Milli-Q water at 6 bar and permeability measurement was then conducted for $1 \mathrm{~h}$ at 5 bar and room temperature $\left(25 \pm 1{ }^{\circ} \mathrm{C}\right)$.

\subsubsection{Estimating the average membrane pore radius}

Analytical grade dextrose, xylose, erythritol and dioxane were purchased from Sigma Aldrich (Castle Hill, NSW, Australia) and used as reference organic solutes to determine the membrane pore size (Table 1). These are hydrophilic organic compounds and thus they do not adsorb to the membrane. Prior to the filtration tests, the membranes were compacted at 18 bar until the flux reached a stable value. The Milli-Q water used for compaction was replaced with 10 L Milli-Q water containing a reference organic solute at concentration equivalent to $80 \mathrm{mg} / \mathrm{L}$ of total organic carbon (TOC). The filtration experiment was then conducted at 4, 6, 8, 10 and 12 bar. At each pressure, the system was stabilized for at least $1 \mathrm{~h}$ prior to the collection of feed and permeate samples $(25 \mathrm{~mL})$ for TOC analysis using a Shimadzu TOC V $\mathrm{CSH}_{\text {Analyser. }}$

Table 2: Properties of the reference organic solutes.

\begin{tabular}{|c|c|c|c|}
\hline Reference organic solutes & MW & ${\text { Stokes radius }(\mathrm{nm})^{\mathrm{a}}}$ & ${\text { Diffusivity }\left(10^{-10} \mathrm{~m}^{2} / \mathrm{s}\right)^{\mathrm{a}}}^{\mathrm{a}}$ \\
\hline Dioxane & 88 & 0.234 & 9.1 \\
\hline Erythritol & 120 & 0.263 & 8.1 \\
\hline Xylose & 150 & 0.290 & 7.4 \\
\hline Dextrose & 180 & 0.324 & 6.6 \\
\hline
\end{tabular}

${ }^{a}$ Reference: [27].

The average pore radius of virgin and chemically cleaned membrane was determined from the rejection data of the reference solutes and the pore transport model that incorporates hindered convection (size exclusion) and diffusion. This method has been widely used to determine the average pore size of nanofiltration membranes [30-32]. It is assumed in the pore transport model that the membrane pores are uniform and cylindrical and the solutes are spherical. Thus, the solute ratio $\left(r_{s}\right)$ to pore size $\left(r_{p}\right), \lambda=r_{s} / r_{p}$, is associated to the partition coefficient $\Phi$ as:

$\Phi=(1-\lambda)^{2}$

The real rejection $\left(\mathrm{R}_{\mathrm{r}}\right)$ can be expressed as a function of the Peclet number $(\mathrm{Pe})$ and the convective hindrance factor $\left(\Phi \mathrm{K}_{\mathrm{c}}\right)$ for spherical solutes: 
$\mathrm{R}_{\mathrm{r}}=1-\left(\frac{\Phi \mathrm{K}_{\mathrm{c}}}{1-\left(1-\Phi \mathrm{K}_{\mathrm{c}}\right) \times \exp (-\mathrm{Pe})}\right)$

$\Phi \mathrm{K}_{\mathrm{c}}$ can be calculated from $\lambda$ and the detailed derivation is available elsewhere [33]. The real rejection can be calculated from the observed rejection $\left(\mathrm{R}_{\mathrm{ob}}\right)$ value by taking into account the concentration polarisation phenomenon using the thin-film theory. $R_{r}$ can be expressed as a function of the solute concentration on the membrane surface $\left(c_{m}\right)$ and permeate $\left(c_{p}\right)$, or the measured solvent flux $\left(\mathrm{J}_{\mathrm{v}}\right)$, the mass transfer coefficient $\left(\mathrm{k}_{\mathrm{f}}\right)$ and $\mathrm{R}_{\mathrm{ob}}$ :

$$
R_{r}=1-\frac{c_{p}}{c_{m}}=\frac{R_{o b} \times \exp \left(\frac{J_{v}}{k_{f}}\right)}{R_{o b} \times \exp \left(\frac{J_{v}}{k_{f}}\right)-R_{o b}+1}
$$

In this study, the mass transfer coefficient $\left(\mathrm{k}_{\mathrm{f}}\right)$ was determined experimentally based on the variation of the membrane flux caused by the addition of a salt solution to a pure water feed [34]. Because the net driving pressure is influenced by the osmotic pressure of the feed solution established on the membrane surface, changes in the permeate flux allows for the determination of the salt concentration on the membrane surface and subsequently the mass transfer coefficient $\mathrm{k}_{\mathrm{f}}$. Filtration experiments were conducted at a cross-flow velocity and solution temperature of $23.6 \mathrm{~cm} / \mathrm{s}$ and $20 \pm 1{ }^{\circ} \mathrm{C}$, respectively. Firstly, the volumetric water flux ( $\left.\mathrm{J}_{\mathrm{v} \text { (water) }}\right)$ was measured using Milli-Q water. Subsequently $\mathrm{NaCl}$ was added to the feed reservoir to obtain $2000 \mathrm{mg} / \mathrm{L}$ and the solute flux $\left(\mathrm{J}_{\mathrm{V} \text { (salt) }}\right)$ was measured. This procedure was conducted at two different applied pressures $(\Delta \mathrm{P}) 10$ and 14 bar. Knowing the salt concentration of the feed and permeate (and thus, the osmotic pressure of the feed $\left(\pi_{f}\right)$ and the permeate $\left.\left(\pi_{p}\right)\right)$, the mass transfer coefficient can be calculated by [34]:

$$
\mathrm{k}_{\mathrm{f}}=\frac{\mathrm{J}_{\mathrm{v} \text { (salt) }}}{\ln \left[\frac{\Delta \mathrm{P}}{\pi_{\mathrm{f}}-\pi_{\mathrm{p}}}\left(1-\frac{\mathrm{J}_{\mathrm{v} \text { (salt) }}}{\mathrm{J}_{\mathrm{v} \text { (water) }}}\right)\right]}
$$




\section{Results and discussion}

\subsection{Impact of caustic cleaning formulations on membrane properties}

\subsubsection{Membrane permeability}

Exposure to a caustic cleaning formulation resulted in a considerable increase in the permeability of the NF270 membrane. A smaller but still notable increase in the permeability of the NF90 membranes could also be observed as a result of caustic cleaning (Figure 1). The more significant increase in the permeability of the NF270 can possibly be attributed to its larger membrane pore size and much thinner active skin layer [35] in comparison to the NF90 membrane. Results in Figure 1 are in good agreement with the literature, which reported that a combination of EDTA and/or SDS and caustic cleaning could lead to permeate flux recovery of more than $100 \%$ compared to the flux prior to cleaning $[9,13,15,36]$.

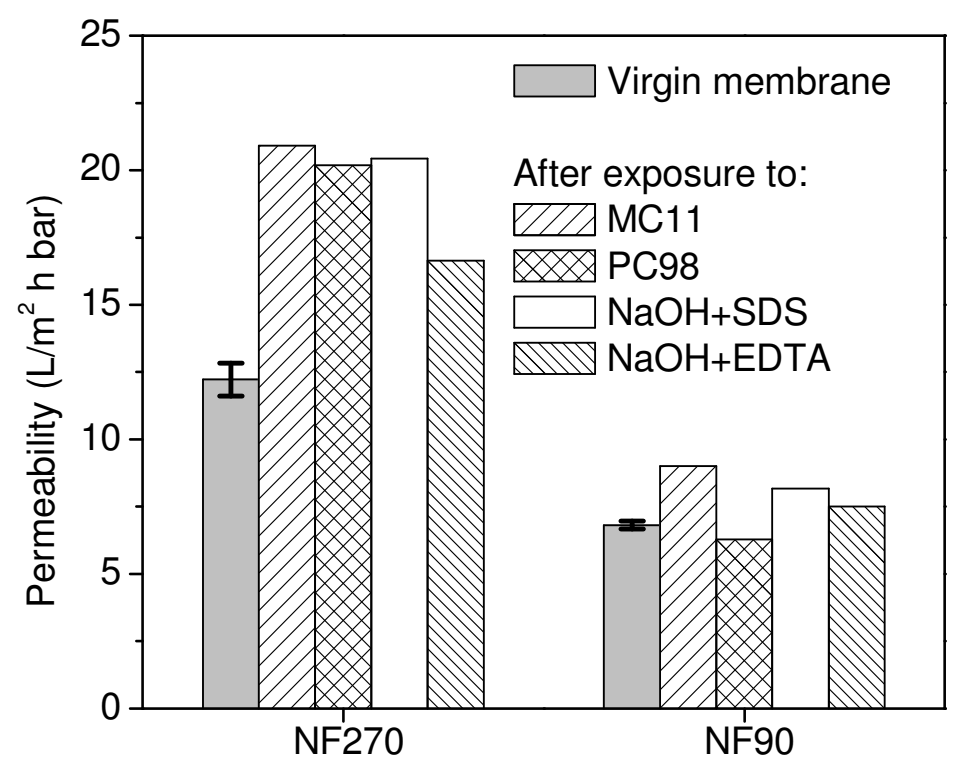

Figure 1

Figure 1: Permeability of the NF270 and NF90 membranes before and after exposure to MC11 $(\mathrm{pH}$ 11.2), PC98 (pH 11), $\mathrm{NaOH}+\mathrm{SDS}$ ( $\mathrm{pH}$ 11.5) and $\mathrm{NaOH}+\mathrm{EDTA}$ ( $\mathrm{pH}$ 11.5). The measurement was conducted with Milli-Q water at 5 bar and $25 \pm 1{ }^{\circ} \mathrm{C}$. The error bars show the standard deviation of three repetitive measurements. 
Recent investigations suggests that two mechanisms can be responsible, either individually or simultaneously, for an increase in permeability after exposing the NF membranes to a caustic cleaning solution. Li and Elimelech conducted cleaning experiments of the NF270 membrane fouled with humic acids using EDTA and SDS at pH 11 and reported a slightly over 100\% permeate flux recovery [36]. The authors postulated that the residual EDTA or SDS on the membrane surface could render the membrane more hydrophilic, leading to a permeate flux value slightly higher than that of the virgin membrane. Variation in the membrane permeability due to chemical cleaning can also be driven by conformational changes in the polymeric matrix of the membrane active skin layer. Simon et al. [9] suggested that, when exposed to a strong caustic cleaning solution, the functional groups (i.e. $\mathrm{COOH}$ and $\mathrm{NH}$ ) can further deprotonate to form more negatively charged moieties within the membrane active skin layer. Therefore, enhanced electrostatic interaction amongst these negatively charged moieties could cause conformational rearrangements of the polyamide structure resulting in an increase in pore size and/or membrane porosity. Due to hysteresis, a considerable increase in permeability after caustic cleaning could be observed, particularly if the membrane has a very thin active skin layer [9]. This study simultaneously examined the impact of caustic cleaning on the membrane surface hydrophilicity and pore size and the results are presented in the next two sections.

\subsubsection{Surface hydrophobicity}

Chemical cleaning using the four different cleaning formulations induced a notable influence on hydrophobicity (or contact angle) of the surface of the NF270 and NF90 membranes (Figure 2). The observed changes in the surface hydrophobicity were dependent on the initial contact angle of the virgin membrane and composition of the chemical cleaning formulation. Chemical cleaning with the PC98 and $\mathrm{NaOH}+\mathrm{SDS}$ formulations resulted in a significant decrease in the contact angle of both the NF270 and NF90 membranes. The PC98 formulation contained amphoteric surfactants, thus, the decrease in the contact angle of the membrane surface observed in Figure 2 could be attributed to the adsorption of

surfactant onto the membrane surface. By contrast, when the NF270 and NF90 membranes were exposed to the MC11 and $\mathrm{NaOH+EDTA}$ cleaning formulations, which do not contain any surfactants, the impact on the membrane surface hydrophobicity was not significant. A small but discernible increase in the surface hydrophobicity of the NF270 membrane could be observed as a result of exposure to the MC11 and $\mathrm{NaOH+EDTA}$ cleaning formulations. On the other hand, because the virgin NF90 is moderately 
hydrophobic, a small decrease in hydrophobicity of the NF90 membrane was observed.

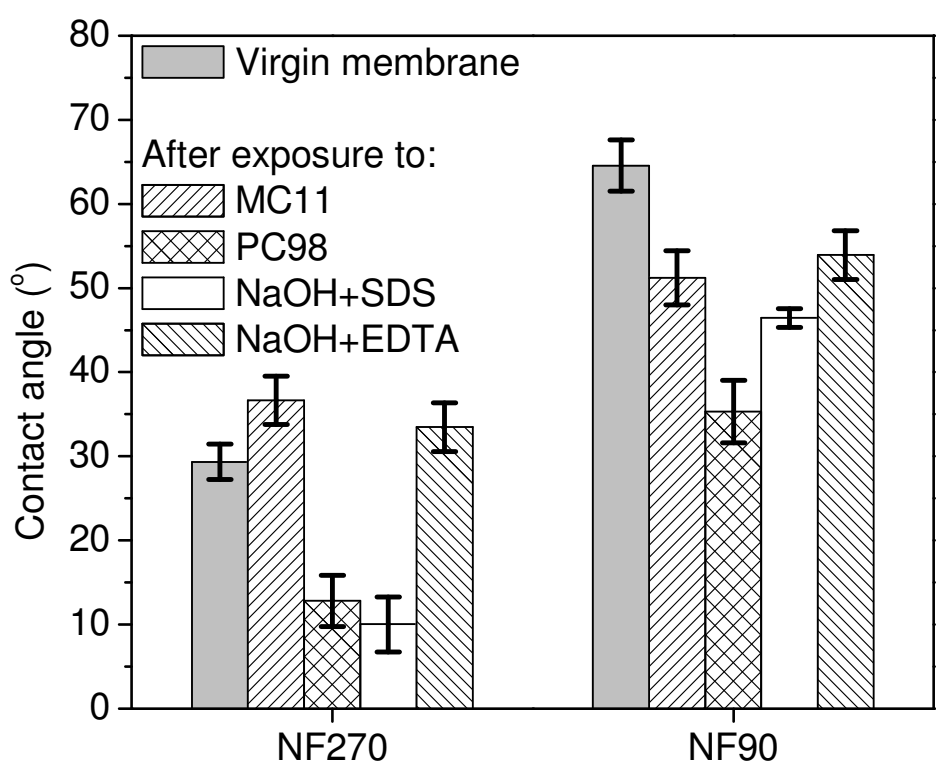

Figure 2

Figure 2: Contact angle of the NF270 and NF90 membranes before and after exposure to MC11 (pH 11.2), PC98 ( $\mathrm{pH} 11), \mathrm{NaOH}+\mathrm{SDS}(\mathrm{pH} 11.5)$ and $\mathrm{NaOH}+\mathrm{EDTA}(\mathrm{pH} 11.5)$. The error bars show the standard deviation of measurements obtained from five droplets on the membrane surface.

Membrane pore size

To determine the average pore size of the NF270 and NF90 membranes, the real rejection of each reference organic solute was calculated from the observed rejection after taking into account concentration polarisation effects (Eq. 4) and the mass tr ansfer coefficient (Eq. 5). Because the model parameters $\Phi \mathrm{K}_{\mathrm{c}}$ and $\mathrm{Pe} / \mathrm{J}_{\mathrm{v}}$ are uniquely related to the real rejection, they can be determined by fitting the real rejection data to the model (Eq. 3) using an optimisation program (Solver, Microsoft ${ }^{\circledR}$ Excel). The parameters $\Phi \mathrm{K}_{\mathrm{c}}$ and $\mathrm{Pe} / \mathrm{J}_{\mathrm{v}}$ are a function of the variable $\lambda$ (ratio of solute radius to membrane pore radius, $r_{s} / r_{p}$ ). Thus, the membrane pore radius was calculated from the $\lambda$ value for each reference solute used in this study. The real rejection of the reference organic solutes of the NF270 and NF90 membranes in virgin condition and after exposure to the caustic cleaning formulation MC11 is presented in Figure 3 and the average pore radii are 
presented in Table 3. In this study, the estimated average pore radius of the virgin NF270 was $0.38 \mathrm{~nm}$ while that of the virgin NF90 was $0.31 \mathrm{~nm}$ (Table 3). The pore size of membrane samples exposed to the MC11 cleaning formulation was also determined to evaluate the effect caustic cleaning on the membrane surface porosity. Exposure to the MC11 cleaning formulation resulted in a small increase in the average pore radius of the NF270 membrane. By contrast, the MC11 formulation did not result in any significant variation in the pore size of the NF90 membrane. These results are consistent with the changes in the membrane permeability and surface hydrophobicity reported above. Indeed, the increase in pore size of the NF270 observed here could explain the significant increase in the membrane permeability after caustic cleaning. On the other hand, because the average pore size of the NF90 membrane was not affected by caustic cleaning, the small increase in permeability of the membrane after exposure to the caustic cleaning formulation can be explained by an increase in the membrane surface hydrophilicity (Figure 2). In addition, the opening of pores smaller than the average pore size could also have affected the increase in the membrane permeability of both membranes.
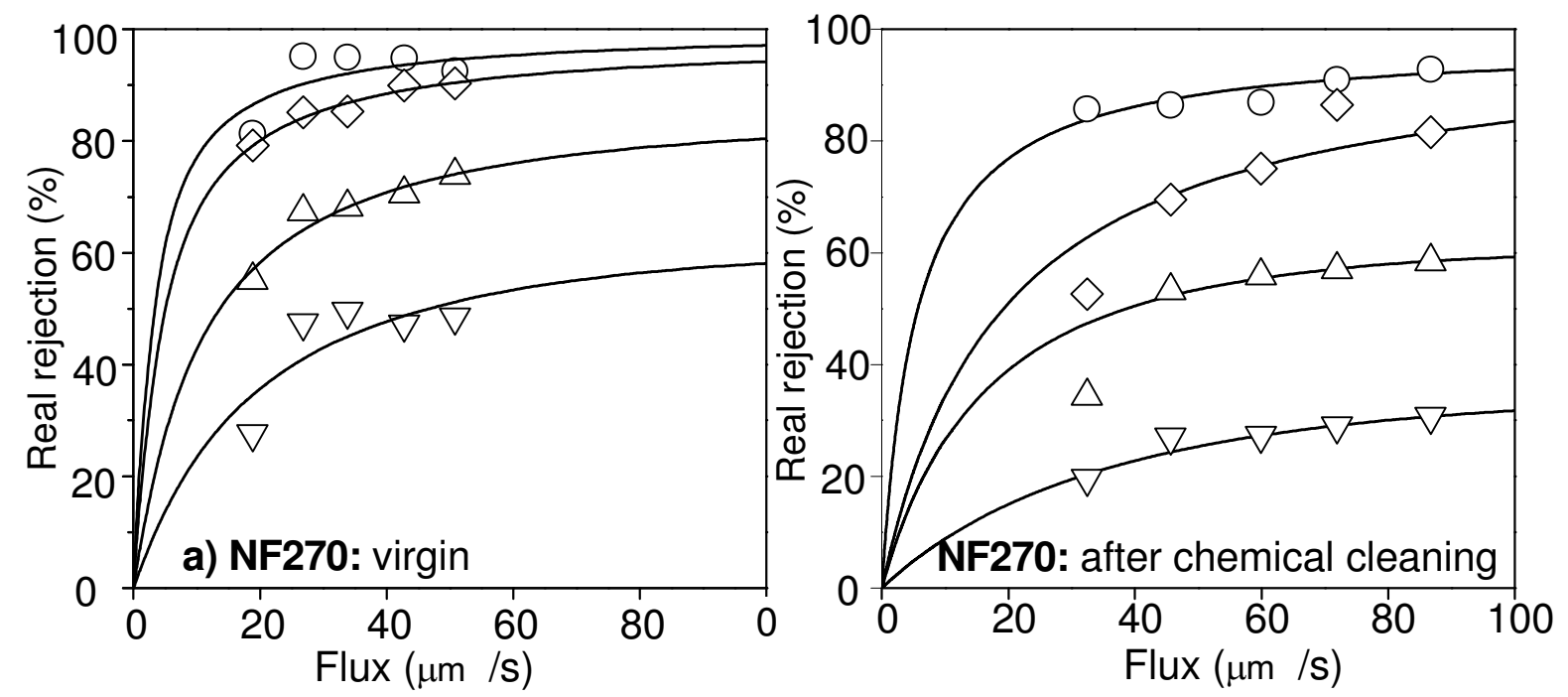

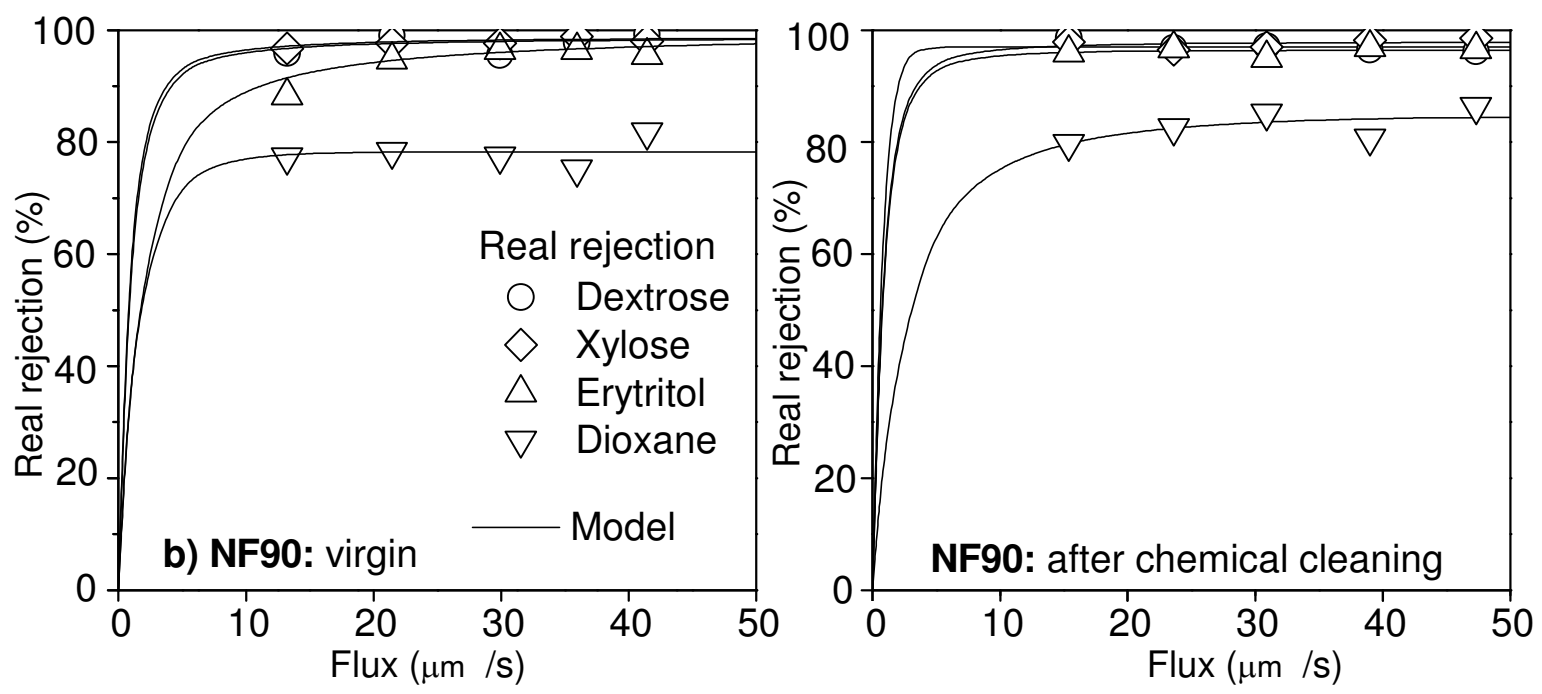

\section{Figure 3}

Figure 3: Real rejection as a function of the permeate flux of the a) virgin and cleaned NF270 and b) virgin and cleaned NF90 membrane. Cross-flow velocity, pH and temperature were $23.6 \mathrm{~cm} / \mathrm{s}, \mathrm{pH} 6$ and $20 \pm 0.1^{\circ} \mathrm{C}$, respectively.

Table 3: Average pore radius of the NF270 and NF90 membranes before and after exposure to the MC11 cleaning formulation.

\begin{tabular}{|c|c|c|c|c|}
\hline \multirow{2}{*}{$\begin{array}{c}\text { Reference organic } \\
\text { solutes }\end{array}$} & \multicolumn{4}{|c|}{ Pore radius (nm) } \\
\cline { 2 - 5 } & $\begin{array}{c}\text { Virgin } \\
\text { NF270 }\end{array}$ & $\begin{array}{c}\text { NF270 after exposure to } \\
\text { MC11 }\end{array}$ & $\begin{array}{c}\text { Virgin } \\
\text { NF90 }\end{array}$ & $\begin{array}{c}\text { NF90 after exposure to } \\
\text { MC11 }\end{array}$ \\
\hline Dextrose & 0.37 & 0.37 & - & - \\
\hline Xylose & 0.37 & 0.43 & 0.29 & 0.30 \\
\hline Erythritol & 0.38 & 0.37 & 0.31 & 0.29 \\
\hline Dioxane & 0.39 & 0.41 & 0.34 & 0.31 \\
\hline \hline $\begin{array}{c}\text { Average pore radius } \\
\text { (nm) }\end{array}$ & 0.38 & 0.40 & 0.31 & 0.30 \\
\hline
\end{tabular}




\subsection{Impact of caustic cleaning formulations on solute rejection}

\subsubsection{Rejection of conductivity}

Caustic chemical cleaning led to a significant decrease in salt rejection (measured by conductivity) by the NF270 membrane, whereas no impact on the conductivity rejection by the NF90 membrane was found (Figure 4). These results are consistent with the impact of caustic cleaning with the MC11 reagent on the average pore size of both the NF270 and NF90 membrane reported in the previous section. Steric hindrance and electrostatic interactions can govern the rejection of ionic solutes by NF membranes [18]. In good agreement with previous studies [9, 10], the impact of caustic cleaning on the surface charge (zeta potential) of both membranes (data not shown) and thus, electrostatic interaction between ionic solutes and the membrane surface, was insignificant. As a result, any changes in conductivity rejection due to caustic chemical cleaning could be due to variation in the membrane pore size. In other words, the significant decrease in conductivity rejection by the NF270 membrane after exposing to caustic cleaning formulation may be due to the enlargement in its pore size as reported in section 3.1.3. Because chemical cleaning did not result in any significant impact on the pore size of the NF90 membrane (section 3.1.3), no discernible variations in conductivity rejection by the NF90 membrane could be observed after the membrane was exposed to various caustic cleaning formulations. It appears that the impact of caustic cleaning formulation was dependent not only on the cleaning $\mathrm{pH}$ but also ingredients of the cleaning formulations. Indeed, the four cleaning formulations caused slightly different effects on conductivity rejection by the NF270 membrane (Figure 4). 


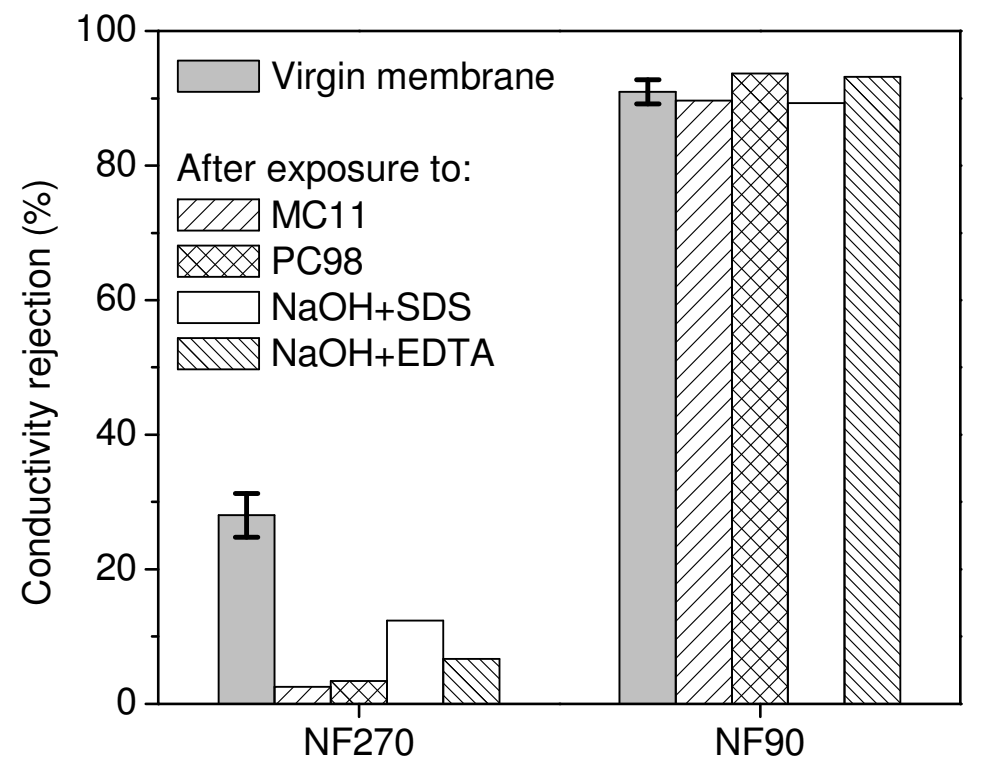

\section{Figure 4}

Figure 4: Conductivity rejection of the NF270 and NF90 membranes at pH 8 before and after exposure to MC11 (pH 11.2), $\mathrm{PC} 98(\mathrm{pH} 11), \mathrm{NaOH}+\mathrm{SDS}(\mathrm{pH} 11.5)$ and $\mathrm{NaOH}+\mathrm{EDTA}(\mathrm{pH}$ 11.5). The feed solution contained $1 \mathrm{mM} \mathrm{CaCl}_{2}, 20 \mathrm{mM} \mathrm{NaCl}$ and $1 \mathrm{mM} \mathrm{NaHCO}_{3}$. Cross-flow velocity, permeate flow and temperature were $23.6 \mathrm{~cm} / \mathrm{s}, 42 \mathrm{~L} / \mathrm{m}^{2} \mathrm{~h}$ and $20 \pm 1{ }^{\circ} \mathrm{C}$, respectively. The error bars show the standard deviation of three measurements.

\subsubsection{Rejection of neutral hydrophilic TrOC}

The membrane porosity and the MW of the TrOC predominantly governed the rejection of hydrophilic and moderately hydrophilic neutral TrOC $(\log \mathrm{D}<3)$ by the NF270 and NF90 membranes. However, the rejection of TrOC can also be influenced by their molecular dimensions [37-39]. Therefore, the equivalent width (defined as $\sqrt{S} / 2$, where $S$ is the surface of rectangle of minimum area enclosing the projection of the molecule on the plane perpendicular to the length-axis) of the TrOC was used in this study to compare their rejection values by the NF270 and NF90 membranes. As shown in Figure 5, the equivalent width of the selected neutral hydrophilic TrOC ranged from 0.60 to $0.93 \mathrm{~nm}$ and the rejection of this group of TrOC by NF increased with their equivalent width by steric hindrance. 
Caustic cleaning formulations led to a significant decrease in the rejection of neutral hydrophilic TrOC by the NF270 membrane (Figure 5a), consistent with a previous study [9]. As discussed before, the NF270 membrane is sensitive to chemical cleaning due to its very thin and loose active skin layer. Therefore, caustic chemical cleaning could affect the average pore size of the NF270 membrane, causing significant variation in the rejection of neutral hydrophilic TrOC (Figure 5a). By contrast, caustic cleaning had no impact on the average pore size and consequently rejection of neutral-hydrophobic TrOC by the NF90 membrane (Figure 5b) because of its thicker active skin layer (section 3.1.3). In addition, for the NF270 membrane, the effect of caustic cleaning on the rejection of TrOC was more significant as their equivalent width decreased. For example, the decrease in rejection of caffeine and estriol by the NF270 due to caustic cleaning was more severe than that of trimethoprim and omeprazole (which have larger equivalent molecular width than the former two compounds) (Figure 5a). It is probable that the increase in pore size of the NF270 membrane due to caustic chemical cleaning affects the convection transport of molecules with small equivalent width. This hypothesis is also consistent with the notable increase in the membrane permeability of the NF270 membrane after exposing to caustic cleaning formulations (Figure 1). 


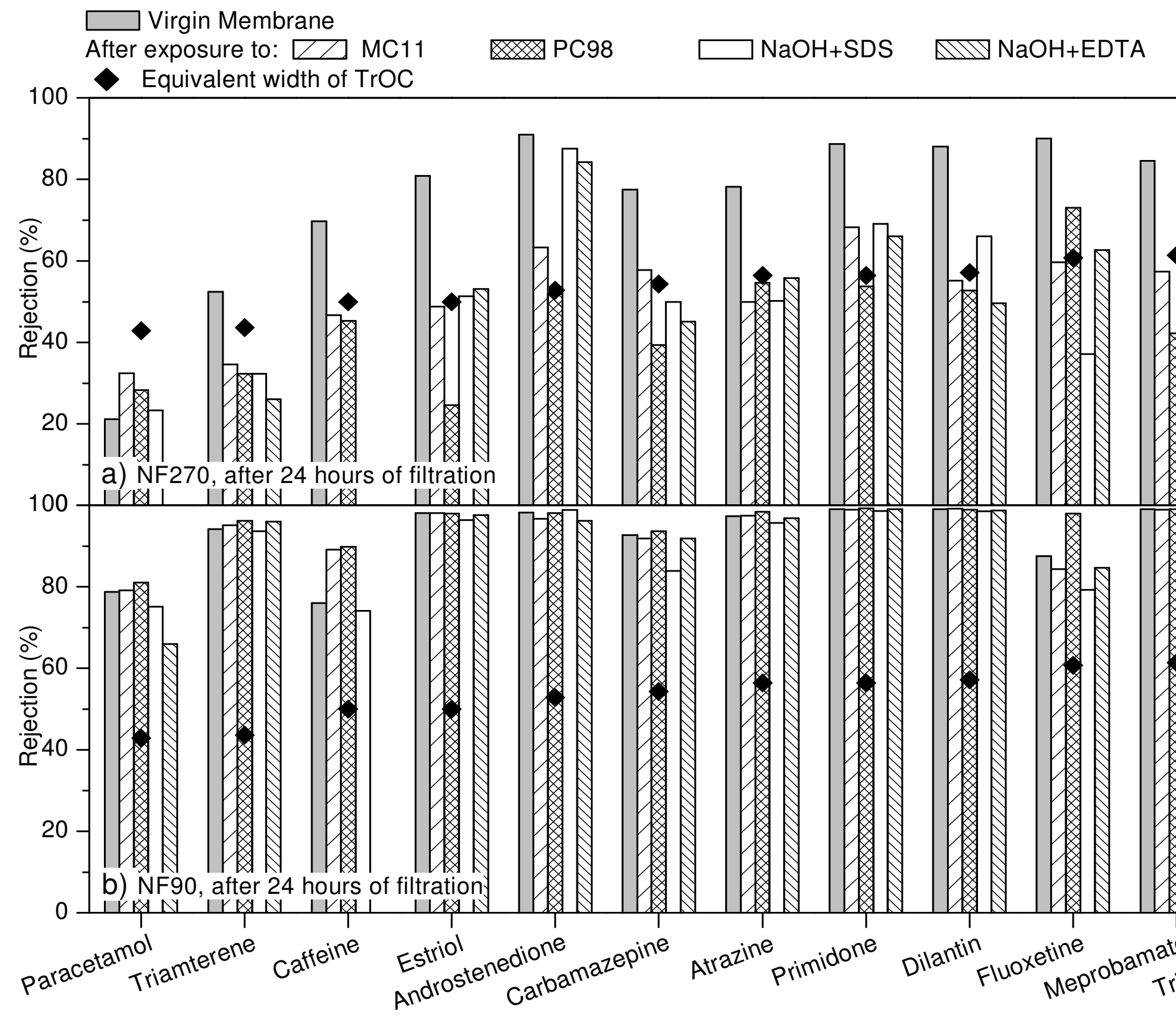

\section{Figure 5}

Figure 5: Rejection of neutral hydrophilic TrOC $(\log \mathrm{D}<3)$ after $24 \mathrm{~h}$ of filtration as a function of the compounds equivalent width by the virgin and cleaned a) NF270 and b) NF90 membrane. Filtration conditions were as in Figure 3.

\subsubsection{Rejection of neutral hydrophobic TrOC}

As shown in Figure 6, at the beginning of the filtration process (i.e. after $1 \mathrm{~h}$ of filtration), adsorption of neutral hydrophobic TrOC (i.e. $\log \mathrm{D} \geq 3$ ) to the NF270 membrane could 
contribute to their overall removal efficiency. However, as the membrane became saturated and the adsorption capacity for these neutral hydrophobic TrOC diminished, the rejection of neutral hydrophobic TrOC after $24 \mathrm{~h}$ of filtration decreased as both convection and diffusion through the NF270 membrane increased. The concentrations of all hydrophobic TrOC in the feed solution were also considerably decreased after $24 \mathrm{~h}$ of filtration (data not shown), which was in good agreement with the literature and indicated the adsorption of these compounds to the membrane $[30,40,41]$.

Of the three groups of TrOC investigated here (i.e. neutral hydrophilic, neutral hydrophobic and negatively charged), caustic cleaning had the most significant impact on the rejection of neutral hydrophobic TrOC by the NF270 membrane (Figure 6). It is noteworthy that the impact of caustic cleaning on rejection of a number of hydrophobic TrOC by the NF270 membrane was only marginal after one hour of filtration. On the other hand, after $24 \mathrm{~h}$ of filtration, the rejection of all hydrophobic TrOC decreased considerably. This phenomenon can be explained by the high initial adsorption rate of hydrophobic TrOC to the membrane polymer, resulting in high retention of these TrOC, regardless of any changes in the membrane pore size due to chemical cleaning. However, after $24 \mathrm{~h}$ of filtration, the rejection of these hydrophobic TrOC by the NF270 membrane was predominantly controlled by size exclusion and the increase in the average membrane pore size of the NF270 membrane in response to the caustic formulated cleaning led to a substantial decrease in the neutral hydrophobic TrOC rejection. In addition, the increase in the membrane hydrophilicity (Figure 2) and/or pore size (Table 3) following caustic cleaning can impact the rate of adsorption and the total possible mass adsorption of TrOC to the NF270 membrane, which could also explain the observed enhanced diffusion of hydrophobic TrOC through the membrane after $24 \mathrm{~h}$ of filtration (Figure 6b) [42, 43]. No impact of chemical cleaning on the rejection of hydrophobic TrOC by the NF90 membrane was found in this study (data not shown), which was also consistent with the little or no variation in the pore size. 


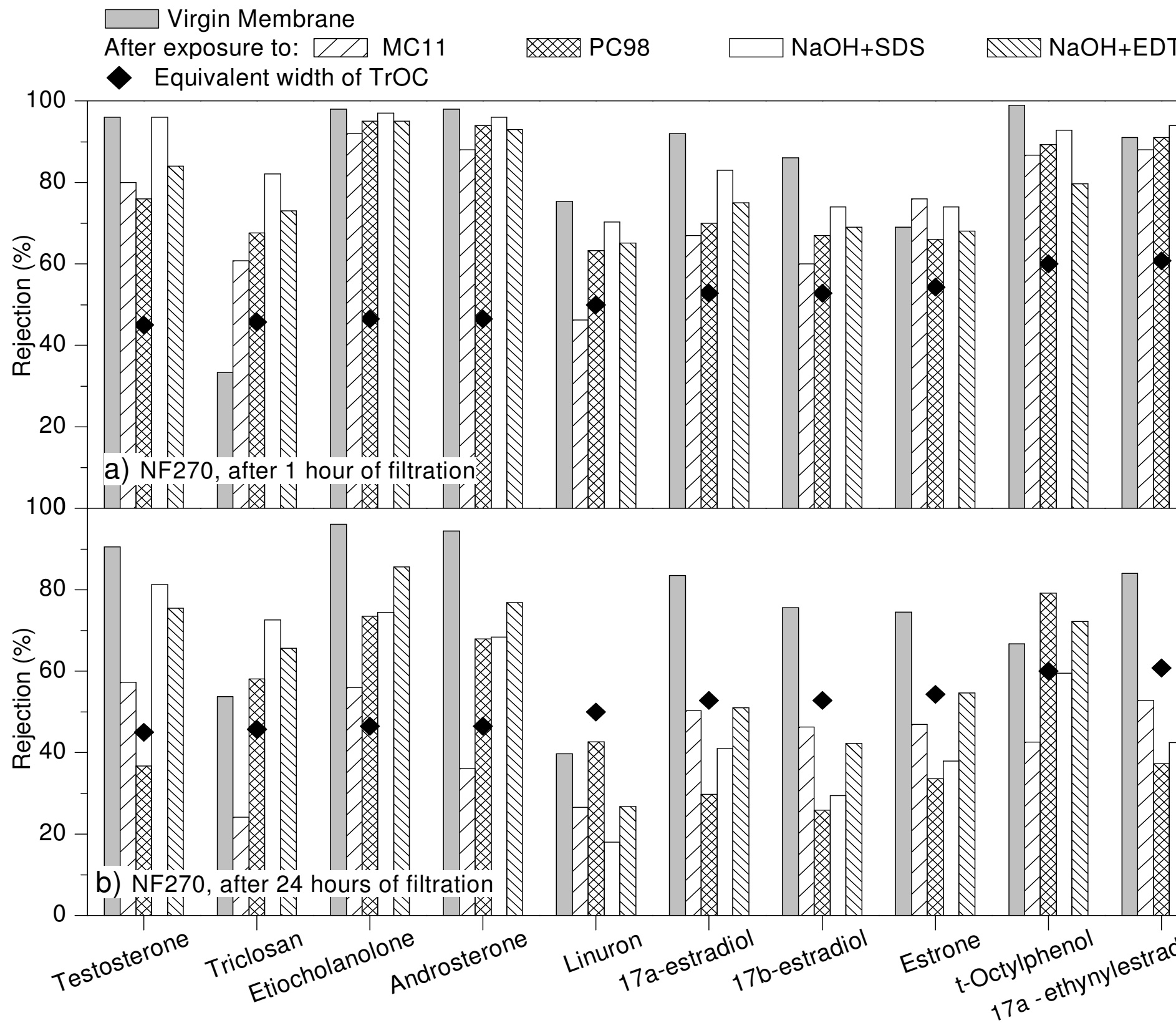

Figure 6

Figure 6: Rejection of neutral hydrophobic TrOC $(\log \mathrm{D} \geq 3)$ as a function of the compounds equivalent width by the virgin and cleaned NF270 membrane after a) one hour and b) $24 \mathrm{~h}$ of filtration. Filtration conditions were as in Figure 3.

\subsubsection{Rejection of negatively charged TrOC}

The rejection of negatively charged TrOC (negatively charged in aqueous solutions at $\mathrm{pH}$ above their $\mathrm{pK}_{\mathrm{a}}$ values) is governed by size and charge exclusion [38]. Because both the NF90 and 
NF270 membranes are also negatively charged under normal pH conditions (i.e. $\mathrm{pH} 6$ - 9) due to acidic functional groups in the membrane polymer [9], they reject negatively charged TrOC by not only size exclusion but also electrostatic repulsion. Consequently, the rejection of negatively charged TrOC by the NF270 and NF90 membrane was the highest among the three groups of TrOC (i.e. neutral hydrophilic, neutral hydrophobic, negatively charged) investigated here (Figure 7). In addition, when comparing the impact of chemical cleaning on the rejection values of the three groups of TrOC (Figure 5-7), it appears that the impact of caustic cleaning on negatively charged TrOC rejection was the least pronounced. Nevertheless, a small but discerniable decrease in the rejection of negatively charged TrOC by the NF270 membrane could be observed after it was exposed to caustic cleaning formulations (Figure 7a). As mentioned before (section 3.2.1), no impact of chemical cleaning chemical cleaning on the charge of the NF270 and NF90 membranes was found in previous studies $[9,10]$. Consequently, observed variations on negatively charged TrOC rejection by the caustic cleaned NF270 membrane could be attributed predominantly to the enlargement of the membrane pore size. Once again, no discernible effect on the rejection of negatively charged TrOC by the NF90 membrane was observed (Figure $7 \mathrm{~b}$ ). This observation is consistent with the impact of caustic cleaning on the pore size of the NF90 membrane (section 3.1.3). 


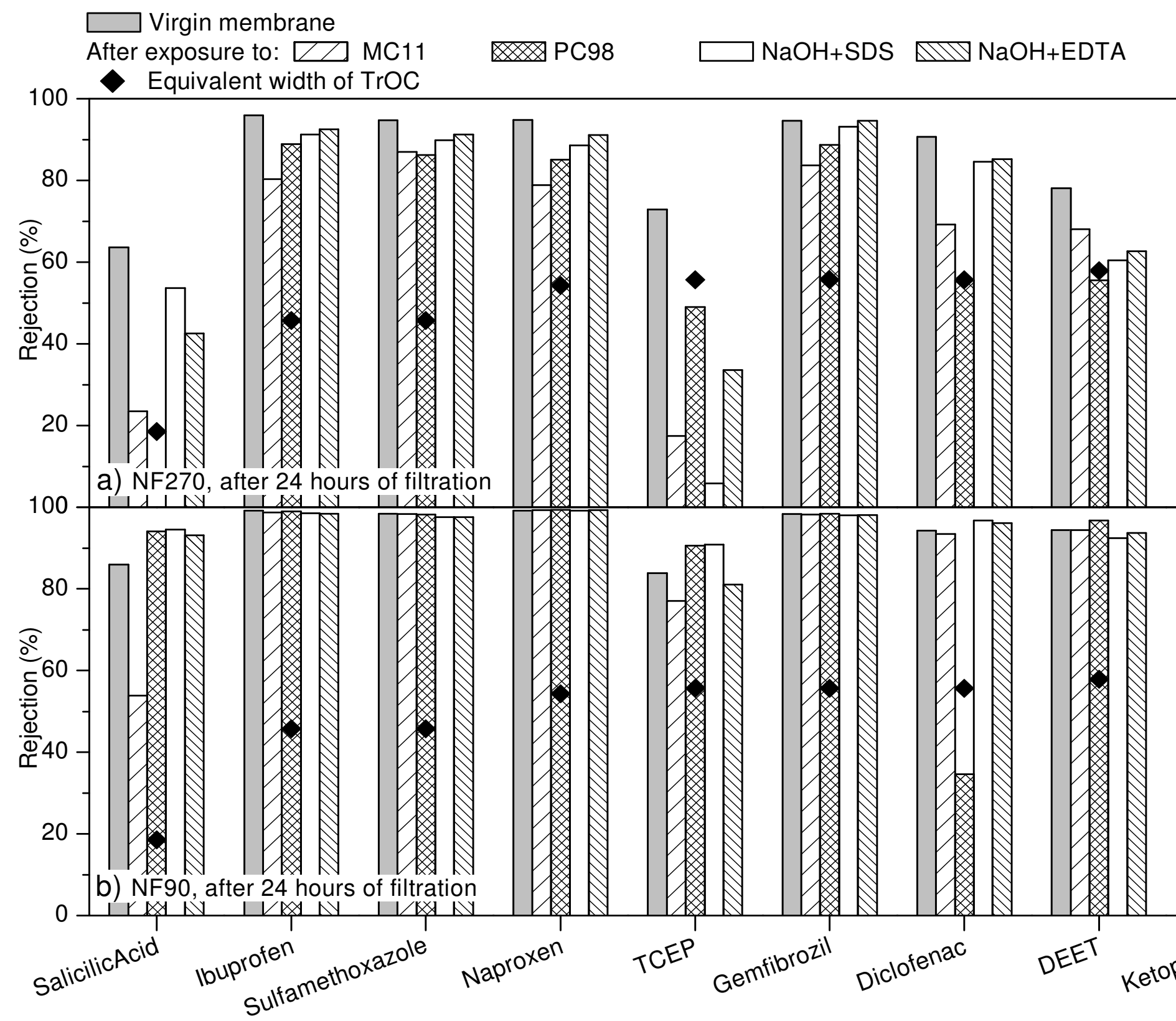

Figure 7

Figure 7: Rejection of negatively charged TrOC after $24 \mathrm{~h}$ of filtration as a function of the compounds equivalent width by the virgin and cleaned a) NF270 and b) NF90 membrane. Filtration conditions were as in Figure 3.

\section{Conclusion}

The impact of caustic cleaning on the pore size and solute rejection was found to be a function of the membrane active skin layer and the chemistry of the cleaning formulation. Caustic cleaning 
led to a small increase in pore size of the NF270 membrane (which has a loose and thin active skin layer), resulting in a notable increase in the permeability and salt passage. By contrast, caustic cleaning did not exert any significant impact on the NF90 membrane (which has a thicker active skin layer). The influence of caustic cleaning on $\operatorname{TrOC}$ rejection was shown to be dependent on their molecular size, charge, and hydrophobicity. The rejection of neutral and hydrophobic TrOC by the NF270 membrane decreased significantly after exposure to caustic cleaning formulation, which is attributed to the increased membrane pore size and hydrophobic interaction with the active skin layer. On the other hand, because the rejection of negatively charged TrOC is predominantly controlled by electrostatic interaction, their rejection was less affected by caustic cleaning.

\section{Acknowledgements}

This study was supported by the Australian Research Council Discovery Project DP0985389.

Dow Chemical, IMDC Group B.V. and NALCO are thanked for the provision of membrane samples and chemical cleaning formulations.

\section{List of symbols}

$\begin{array}{ll}\mathrm{c}_{\mathrm{f}} & \text { Solute concentration in feed }\left(\mathrm{kg} / \mathrm{m}^{3}\right) \\ \mathrm{c}_{\mathrm{m}} & \text { Solute concentration on the membrane surface in feed side }\left(\mathrm{kg} / \mathrm{m}^{3}\right) \\ \mathrm{c}_{\mathrm{p}} & \text { Solute concentration in permeate }\left(\mathrm{kg} / \mathrm{m}^{3}\right) \\ \mathrm{J}_{\mathrm{v}} & \text { Solvent flux }\left(\mathrm{L} / \mathrm{m}^{2} \mathrm{~s}\right) \\ \mathrm{J}_{\mathrm{v}(\text { salt })} & \text { Salt flux }\left(\mathrm{kg} / \mathrm{m}^{2} \mathrm{~s}\right) \\ \mathrm{J}_{\mathrm{v}(\text { water })} & \text { Water flux }\left(\mathrm{L} / \mathrm{m}^{2} \mathrm{~s}\right) \\ \mathrm{k}_{\mathrm{f}} & \text { Mass transfer coefficient }(\mathrm{m} / \mathrm{s}) \\ \mathrm{Pe} & \text { Peclet number }(\text { dimensionless }) \\ \mathrm{R}_{\mathrm{ob}} & \text { Observed rejection }(\%) \\ \mathrm{r}_{\mathrm{p}} & \text { Pore radius }(\mathrm{m}) \\ \mathrm{R}_{\mathrm{r}} & \text { Real rejection }(\%) \\ \mathrm{r}_{\mathrm{s}} & \text { Solute radius }(\mathrm{m}) \\ \pi_{\mathrm{f}} & \text { Osmotic pressure feed }\left(\mathrm{Kg} / \mathrm{m} \mathrm{s}^{2}\right) \\ \pi_{\mathrm{p}} & \text { Osmotic pressure permeate }\left(\mathrm{Kg} / \mathrm{m} \mathrm{s}^{2}\right) \\ \Delta \mathrm{P} & \text { Applied pressure }\left(\mathrm{Kg} / \mathrm{m} \mathrm{s}{ }^{2}\right) \\ \lambda & \text { Lambda (dimensionless) }\end{array}$


$\Phi \mathrm{K}_{\mathrm{c}} \quad$ Convective hindrance factor (dimensionless)

\section{References}

[1] C. Fernández, M. González-Doncel, J. Pro, G. Carbonell, J.V. Tarazona, Occurrence of pharmaceutically active compounds in surface waters of the henares-jarama-tajo river system (Madrid, Spain) and a potential risk characterization, Sci. Total. Environ. 408 (2010) 543-551.

[2] Y. Valcárcel, S. González Alonso, J.L. Rodríguez-Gil, A. Gil, M. Catalá, Detection of pharmaceutically active compounds in the rivers and tap water of the Madrid region (Spain) and potential ecotoxicological risk, Chemosphere 84 (2011) 1336-1348.

[3] A.Y.-C. Lin, S.C. Panchangam, P.-S. Ciou, High levels of perfluorochemicals in Taiwan's wastewater treatment plants and downstream rivers pose great risk to local aquatic ecosystems, Chemosphere 80 (2010) 1167-1174.

[4] M.S. Fram, K. Belitz, Occurrence and concentrations of pharmaceutical compounds in groundwater used for public drinking-water supply in California, Sci. Total. Environ. 409 (2011) 3409-3417.

[5] S.D. Kim, J. Cho, I.S. Kim, B.J. Vanderford, S.A. Snyder, Occurrence and removal of pharmaceuticals and endocrine disruptors in South Korean surface, drinking, and waste waters, Water Res. 41 (2007) 1013-1021.

[6] R.P. Schwarzenbach, B.I. Escher, K. Fenner, T.B. Hofstetter, C.A. Johnson, U. von Gunten, et al., The challenge of micropollutants in aquatic systems, Science 313 (2006) 1072-1077.

[7] T. Fujioka, S.J. Khan, Y. Poussade, J.E. Drewes, L.D. Nghiem, N-nitrosamine removal by reverse osmosis for indirect potable water reuse - A critical review based on observations from laboratory-, pilot- and full-scale studies, Sep. Purif. Technol. 98 (2012) 503-515.

[8] A. Al-Amoudi, R.W. Lovitt, Fouling strategies and the cleaning system of NF membranes and factors affecting cleaning efficiency, J. Membr. Sci. 303 (2007) 4-28.

[9] A. Simon, W.E. Price, L.D. Nghiem, Influence of formulated chemical cleaning reagents on the surface properties and seperation efficiency of nanofiltration membranes, J. Membr. Sci. 432 (2013) 78-82. 
[10] A. Simon, W.E. Price, L.D. Nghiem, Effects of chemical cleaning on the nanofiltration of pharmaceutically active compounds (PhACs) Sep. Purif. Technol. 88 (2012) 208-215.

[11] N. Porcelli, S. Judd, Chemical cleaning of potable water membranes: A review, Sep. Purif. Technol. 71 (2010) 137-143.

[12] B. Van der Bruggen, M. Mänttäri, M. Nyström, Drawbacks of applying nanofiltration and how to avoid them: A review, Sep. Purif. Technol. 63 (2008) 251-263.

[13] R. Liikanen, J. Yli-Kuivila, R. Laukkanen, Efficiency of various chemical cleanings for nanofiltration membrane fouled by conventionally-treated surface water, J. Membr. Sci. 195 (2002) 265-276.

[14] S.S. Madaeni, S. Samieirad, Chemical cleaning of reverse osmosis membrane fouled by wastewater, Desalination 257 (2010) 80-86.

[15] A. Al-Amoudi, P. Williams, A.S. Al-Hobaib, R.W. Lovitt, Cleaning results of new and fouled nanofiltration membrane characterized by contact angle, updated DSPM, flux and salts rejection, Appl. Surf. Sci. 254 (2008) 3983-3992.

[16] A. Simon, W.E. Price, L.D. Nghiem, Changes in surface properties and separation efficiency of a nanofiltration membrane due to repeated fouling and chemical cleaning cycles, Sep. Purif. Technol. 113 (2013) 42-50.

[17] S. Hong, M. Elimelech, Chemical and physical aspects of natural organic matter (NOM) fouling of nanofiltration membranes, J. Membr. Sci. 132 (1997) 159-181.

[18] L.D. Nghiem, A.I. Schäfer, M. Elimelech, Nanofiltration of hormone mimicking trace organic contaminants, Sep. Sci. Technol. 40 (2005) 2633-2649.

[19] A.J.C. Semião, A.I. Schäfer, Removal of adsorbing estrogenic micropollutants by nanofiltration membranes. Part A—Experimental evidence, J. Membr. Sci. 431 (2013) 244-256.

[20] Dow Chemicals, FILMTEC NF270-400 Nanofiltration Element, (2011) available from http://www.lenntech.com/Data-sheets/Dow-Filmtec-NF270-400.pdf.

[21] M.J.M. Wells, Log DOW : Key to understanding and regulating wastewater-derived contaminants, Environ. Chem. 3 (2006) 439-449. 
[22] A. Simon, W.E. Price, L.D. Nghiem, Implications of membrane fouling toward the removal of the pharmaceutical sulfamethoxazole by nanofiltration processes, Zhejiang Univ. Sci. A. 12 (2011) 575-582.

[23] Dow Chemicals, Cleaning Steps, (2012) available from http://www.dowwaterandprocess.com/support_training/literature_manuals/filmtec_manual.htm.

[24] Floclean MC11, product sheet, (2012) available from http://www.kebansu.com/media/data/013-2-FLOCLEAN-MC11-10-2011.pdf.

[25] A. Al-Amoudi, P. Williams, S. Mandale, R.W. Lovitt, Cleaning results of new and fouled nanofiltration membrane characterized by zeta potential and permeability, Sep. Purif. Tech. 54 (2007) 234-240.

[26] G. Kang, C. Gao, W. Chen, X. Jie, Y. Cao, Q. Yuan, Study on hypochlorite degradation of aromatic polyamide reverse osmosis membrane, J. Membr. Sci. 300 (2007) 165-171.

[27] A. Ettori, E. Gaudichet-Maurin, J.-C. Schrotter, P. Aimar, C. Causserand, Permeability and chemical analysis of aromatic polyamide based membranes exposed to sodium hypochlorite, $\mathrm{J}$. Membr. Sci. 375 (2011) 220-230.

[28] A. Alturki, N. Tadkaew, J.A. McDonald, S.J. Khan, W.E. Price, L.D. Nghiem, Combining MBR and NF/RO membrane filtration for the removal of trace organics in indirect potable water reuse applications, J. Membr. Sci. 365 (2010) 206-215.

[29] T. Mariam, L.D. Nghiem, Landfill leachate treatment using hybrid coagulationnanofiltration processes, Desalination 250 (2010) 677-681.

[30] L.D. Nghiem, A.I. Schäfer, M. Elimelech, Removal of natural hormones by nanofiltration membranes: $\square$ Measurement, modeling, and mechanisms, Environ. Sci. Technol. 38 (2004) 18881896.

[31] M.J. López-Muñoz, A. Sotto, J.M. Arsuaga, B. Van der Bruggen, Influence of membrane, solute and solution properties on the retention of phenolic compounds in aqueous solution by nanofiltration membranes, Sep. Purif. Technol. 66 (2009) 194-201.

[32] M. Xie, L.D. Nghiem, W.E. Price, M. Elimelech, Comparison of the removal of hydrophobic trace organic contaminants by forward osmosis and reverse osmosis, Water Res. 46 (2012) 2683-2692. 
[33] P.M. Bungay, H. Brenner, The motion of a closely-fitting sphere in a fluid-filled tube, Int. J. Multiphase Flow 1 (1973) 25-56.

[34] I. Sutzkover, D. Hasson, R. Semiat, Simple technique for measuring the concentration polarization level in a reverse osmosis system, Desalination 131 (2000) 117-127.

[35] V. Freger, J. Gilron, S. Belfer, TFC polyamide membranes modified by grafting of hydrophilic polymers: an FT-IR/AFM/TEM study, J. Membr. Sci. 209 (2002) 283-292.

[36] Q. Li, M. Elimelech, Organic fouling and chemical cleaning of nanofiltration membranes: measurements and mechanisms, Environ. Sci. Technol. 38 (2004) 4683-4693.

[37] K.O. Agenson, J.-I. Oh, T. Urase, Retention of a wide variety of organic pollutants by different nanofiltration/reverse osmosis membranes: Controlling parameters of process, J. Membr. Sci. 225 (2003) 91-103.

[38] B. Van der Bruggen, J. Schaep, D. Wilms, C. Vandecasteele, Influence of molecular size, polarity and charge on the retention of organic molecules by nanofiltration, J. Membr. Sci. 156 (1999) 29-41.

[39] L.D. Nghiem, A.I. Schäfer, M. Elimelech, Pharmaceutical retention mechanisms by nanofiltration membranes, Environ. Sci. Technol. 39 (2005) 7698-7705.

[40] C. Bellona, J.E. Drewes, P. Xu, G. Amy, Factors affecting the rejection of organic solutes during NF/RO treatment - a literature review, Water Res. 38 (2004) 2795-2809.

[41] L.D. Nghiem, P.J. Coleman, NF/RO filtration of the hydrophobic ionogenic compound triclosan: Transport mechanisms and the influence of membrane fouling, Sep. Purif. Technol. 62 (2008) 709-716.

[42] K. Kimura, G. Amy, J. Drewes, Y. Watanabe, Adsorption of hydrophobic compounds onto NF/RO membranes: an artifact leading to overestimation of rejection, J. Membr. Sci. 221 (2003) 89-101.

[43] L.D. Nghiem, A.I. Schäfer, T.D. Waite, Adsorptive interactions between membranes and trace contaminants, Desalination 147 (2002) 269-274. 